\title{
O Cavalete, a Tela e o Branco: Introdução \\ À Autoria na Rede Eletrônica
}

(The Rack, the Screen, the Memory: Considerations

on Authorship in the Net)

\author{
Lucília Maria Sousa Romão \\ (Faculdade de Filosofia, Ciências e Letras de Ribeirão \\ Preto da Universidade de São Paulo)
}

\begin{abstract}
RESUMO: $O$ presente artigo discute a autoria na rede eletrônica, focando especialmente a questão da memória, do arquivo e do sujeito. À luz da Análise do Discurso de matriz francesa e apoiada no conceito de heterogeneidade enunciativa (Authier-Revuz), analiso um corpus lingüístico coletado em 2004, em um blog político de nome Mexidão. A análise indicia, provisoriamente, que a topologia do hipertexto, a rapidez dos acessos e a estrutura textual do diário intimo eletrônico criam a imagem de um sujeito-navegador em permanente trânsito.
\end{abstract}

PALAVRAS-CHAVE: heterogeneidade; memória; sujeito; discurso; ideologia.

ABSTRACT: The present article discusses the authorship in the electronic net, especially focusing the subject of the memory, of the file and of the subject. To the light of the Analysis of the Discursive of French and leaning head office in the beterogeneity concept (Authier-Revuz), I analyze a linguistic corpus collected in 2004, in a political blog of name Mexidão. The analysis indicates, provisorily, that the topology of the hipertext, the speed of the accesses and the textual structure of the electronic intimate diary create the image of a subject-navigator in permanent traffic.

KEY-WORD: heterogeneity; memory; subject; discourse; ideology.

"Sobre o cavalete, o pintor colocou uma tela branca. Olha-a como a um espelho. A tela é aquele único espelho que não pode reflectir a imagem do que está diante de si, daquilo que com ele se confronta. A tela só mostrará a imagem do que apenas noutro lugar é encontrável", seguindo esse fragmento de Saramago (1998:508), a tela, em seu silêncio desejante de tinta, não reproduz a realidade nem a reflete exatamente como um espelho. Ela abrigará imagens do que está 
vivo em outro lugar e se desloca para a tela quando a mão da memória do artista se deitar no tecido virgem. Então, a corrente migratória de imagens, traços, figuras ganha corpo, inscrevendo formas e sentidos no vazio do branco, afetados pela "representação de uma memória", como diz o autor. É a memória que se desenha, ao desenhar, no movimento do artista, o mundo que ele suporia digno de pintar, pois "ao pintar, o pintor não vê o mundo, vêe a representação dele na memória que dele tem”.

Tomo emprestada essa definição sobre pintura por dois motivos: primeiro porque ela dialoga com o processo de constituição do discurso, ou seja, há sempre uma superfície da memória que é mobilizada e reclamada para que as palavras façam sentido quando inscritas na tela do papel. Segundo, porque ela me parece adequada para retratar a textualidade eletrônica, em cuja topologia links remetem-se uns aos outros e colam-se mutuamente o tempo todo, construindo uma teia de nós e conexões, que só fazem e constroem sentidos para o sujeito se ele tiver acesso à memória e ao arquivo. A tela do monitor apagada, em seu negrume, no cavalete da escrivaninha, também guarda o que "noutros tantos lugares é encontrável", já que ao clicar, o navegador vê o mundo do ciberespaço como uma representação virtualizada e inscreve (-se) em discursos que fazem falar sentidos e possibilidades de roteiros e cartografia, atualizando permanentemente o já-lá.

A questão do discurso reclama a compreensão de que sempre há justaposição de vozes no molejo do intradiscurso sobre o interdiscurso, processo esse de manutenções e rupturas de sentido. Várias camadas de tinta são depositadas em superfícies já coloridas e, assim, uma pátina de vozes se forma, ora deixando ver, por sobre uma cor, os riscados de outra tonalidade; ora uma cor apagando quase por completo a superfície de tinta em que se fixou. Conforme Orlandi (1997:11): “(...) no discurso há sempre um discurso outro, função da relação de todo dizer com a ideologia (com a exterioridade, com o interdiscurso). O dizer, logo, nunca é só um". Assim, pensar a exterioridade do dizer e a sua relação com o interdiscurso e com a heterogeneidade na malha digital, recoloca a questão dos limites, fronteiras e contradições do arquivo, tema que será contemplado a seguir.

Por agora, vale marcar que as duas telas - a branca à espera do batismo das tintas e a negra na expectativa de ser ligada - se sustentam apoiadas pela metáfora da janela e pelo que será visto do lado de lá, a paisagem a ser construída e desvelada sob o signo da memória do pintor e/ou nave- 
gador. Os dois lados da janela (e do arquivo) estabelecendo conexões, passagens e deslocamentos, instalam sentidos de trânsito, possibilitando fugidios movimentos de recortes plásticos e inscrições verbais, pois, como mostra Marcuschi (1999): "O bipertexto se caracteriza, pois, como um processo de escrituralleitura eletrônica multilinearizado, multiseqüencial e indeterminado, realizado em um novo espaço".

Construção e ruptura do desenho mágico composto letra a letra, traço a traço, link a link com o sujeito se inscrevendo na rede, instalando (-se) uma nova discursividade a ser tateada, nesse trabalho, a partir de conceitos caros à escola francesa de Análise do Discurso, tais como sujeito, ideologia, memória, arquivo e historicidade. Telas, brancos e buracos negros na/da rede. Busco aqui elaborar um estudo sobre a textualidade eletrônica e a autoria nos blogs, ainda que saiba correr o risco de perder-me nos entremeios dos links e na opacidade de tantas vozes heterogêneas que fal(t)am nos meandros da net.

\section{Arquivo: questão de ideologia e memória}

Para começar, tomo a formulação de Pêcheux (1982:56-57) sobre o arquivo: "(...) há, entretanto, fortes razões para se pensar que os conflitos explícitos remetem em surdina a clivagens subterrâneas entre maneiras diferentes de ler 0 arquivo (entendido aqui como 'campo de documentos pertinentes e disponíveis sobre uma questão')'. Ela contribui muito para a compreensão da discursividade eletrônica, pois a internet nada mais é do que uma cadeia globalizada de arquivos digitalizados, interconectados e dispostos em links organizados em endereços fixos, cuja permanência on-line não é eterna, aliás, tem duração bastante volátil. A atualidade da voz do autor ecoa com propriedade, posto que, em se tratando do ciberespaço, é possível dizer que o campo de documentos pertinentes a uma questão é crivado por regiões do interdiscurso, que nos remetem ao recorte de informações e à "escolha" prévia do material selecionado para alimentar a rede. Há informações que merecem destaque, dados que devem se constituir como material para estar on-line e recursos verbais ou não-verbais que merecem ser envelopados dentro deste ou daquele arquivo etiquetado com o selo www.

Esse olhar atento de Pêcheux às "clivagens subterrâneas" chama a atenção para um jogo de dupla face. De um lado há recorte e seleção de certos 
textos, imagens e informações que instalam sentidos na Internet e estão autorizados a entrar na rede de arquivos e aceitos para circular nos sites, bancos de dados, portais etc. Por outro lado, também é verdade que outros tantos sentidos são desprezados e eliminados, pois ao falar X, sempre calamos Y. Essa dupla face indica que há um direcionamento de tais seleções, processo este que não diz respeito apenas a escolhas meramente técnicas de tamanho, extensão, compatibilidade de sistemas etc, mas que é engendrado pela ideologia como o processo que naturaliza e legitima certos sentidos, apagando outros, indesejáveis ou tidos como não relevantes. Tal questão é política e ideológica e diz respeito ao fato de que os arquivos, em geral, e os eletrônicos, em particular, não podem ser interpretados apenas do ponto de vista técnico, mas, sobretudo, merecem atenção pela instância ideológica que os constituem.

O recorte de dados e informações compreende essa dimensão de acervo manipulado, construído por outro, remexido pelo filtro alheio, isto é, disponibiliza-se uma zona da memória já lida, recolhida e selecionada por outro(s) sujeito(s). Tal seleção envolve a dimensão de que há regiões de dizer autorizadas e outras censuradas, inscritas historicamente, que não são quaisquer umas, mas afetadas pela ideologia e por relações de poder. Esse movimento de autorização e interdição fica mais plausível e é mais explícito na textualidade impressa, se tomarmos, por exemplo, os fatos que se seguem: o texto do jornalista não ser aceito pelo editor, um livro recusado por uma editora, um artigo não indicado para a publicação em uma revista científica. Nesses casos, há um outro, imaginariamente no lugar de autoridade, que corta, que se constitui como a chancela da legitimação, que aceita ou recusa certos sentidos.

No caso da textualidade eletrônica, esse lugar não é ocupado formalmente por um outro, posto que o texto não precisa ser aceito para estar em um blog, mas não é por isso que cairemos na formulação simplista de que todos os sentidos estão lá ou de que tudo é possível simbolicamente na rede. O sujeito, em sendo interpelado pela ideologia, ocupa aqui a posição de censor de si mesmo, em um movimento que Pêcheux definiu como dois esquecimentos (1969). Sujeito, ideologia, arquivo e memória são conceitos fundamentais para observar a inscrição da virtualidade nos atos de linguagem e de contribuir para demonstrar que apenas o arcabouço técnico não dá conta da complexidade que ora observamos. Sobre isso Pêcheux (1982: 55/56) afirma: 
"o discursivo informaticamente marcado sob a forma dos 'dados textuais' não tem, efetivamente, a mesma relação nos procedimentos lógico-matemáticos que este outro tipo de dados, de natureza quantitativa, utilizados em economia, em demografia, em história etc.".;

Para evitar o risco do reducionismo técnico, tão freqüente àqueles que apenas processam programas ou manuseiam execuções de softwares, vale ampliar o entendimento da rede eletrônica para além de seu caráter funcional. Ou seja, é preciso esticar o horizonte em torno da formação e constituição da rede em sua dimensão ideológica, histórica e discursiva, interpretando os indícios inscritos na arena de silício da pós-modernidade e desvelando sentidos da/na topologia fragmentada e nos arquivos interconectados da rede. Outra vez, a voz do autor se faz presente:

"É, em particular, dizer os 'literatos': vocês acreditam poder ficar assim à distância da adversidade que ameaça bistoricamente a memória e o pensamento? Acreditam poder ficar tanto tempo ainda protegidos, na casa de seu mundo de arquivo particular?

E é também dizer aos 'cientistas': vocês, a quem chama de fabricantes-utilizadores de instrumentos, vocês acreditam poder ainda por muito tempo escapar à questão de saber para que vocês servem e quem os utiliza?". (Pêcheux 1982:61)

Assim, pensar a questão do arquivo (impresso e eletrônico) dialoga com uma reflexão sobre o poder em sua essência. Poder de disponibilizar instrumentos de permanência de certos sentidos, de recolher ou aniquilar a memória, de burocratizar e oficializar informações, de constituir lugares de resistência, de autorizar que alguns sentidos sejam divulgados e outros não, de servir para que algumas vozes sejam caladas ou insurjam na infomaré. Enfim, poder de selecionar interesses, de emprestar prestígio e de dar link para que redes de conexões se construam ou se dissolvam.

Dessa forma, o sujeito na malha digital é aqui compreendido como sujeito do discurso em relação a um poder, posição inscrita pela ideologia e pela memória e constituída em condições de produção datadas historicamente. Afetado pela navegação em uma superfície de dados prefixados anteriormente, o sujeito se movimenta na rede do já-dado, já-dito e játraçado por um outro sujeito, embrenhando-se em nós que já foram atados por outrem. Assim, o poder dos acessos e dos acessamentos, tantas vezes maculado pelo chavão da liberdade, se limita ao gesto de inscrever-se em locais que já foram autorizados, previamente lidos e acomodados. Também 
vale a ressalva de que o poder de que falo não aceita todos igualmente nem é distribuído de maneira igualitária em nosso país, diga-se de passagem, país em que, na melhor das hipóteses, a estatística mais otimista nos leva à casa de 9\% de incluídos digitalmente. De acordo com Melo (2004: 137), o mito da acessabilidade pode ser compreendido assim:

"De fato, tecnicamente, o ciberespaço aceita todos. Qualquer grupo ou indivíduo, não importando sua origem geográfica e social, pode investir na rede por conta própria e difundir nela todo tipo de informaşão que ache digna de interesse, desde que para isto lance mão de um minimo de competências técnicas. As facilidades para lanşar uma publicaşão na web são, sem sombra de dívida, infinitamente maiores do que na mídia tradicional."

Mas, como já disse anteriormente, não me interessa discutir a questão meramente técnica, por isso, continuo a transcrever a autora:

"Embora no ciberespaço cada sujeito seja efetivamente um potencial produtor de informação, a Análise do Discurso (AD) vai nos mostrar que mesmo que a rede abrigue uma pluralidade de idéias, de pontos de vista, isso não é suficiente para que baja uma democratização dos discursos. Não basta as idéias estarem lá depositadas, é preciso que elas circulem, que tomem corpo, que elas reverberem. Isto é, que elas entrem na ordem do discurso e não fiquem apenas 'à deriva na superfície das águas"

Por fim, o poder em questão circunscreve ao sujeito-navegador a possibilidade de ele misturar-se a vozes heterogêneas dissolvidas e esgarçadas nos fios da rede, fundindo-se a elas para assentar-se no mesmo lugar ou desinstalando-as para confrontá-las. Não por acaso, quase todos os sites têm espaço para que o internauta escreva, deixe seu rastro de voz, interaja com o conteúdo da página e se constitua voz materializada que deixa rastro de pegadas via escrita. E, como o texto eletrônico não apresenta páginas a serem viradas como acontece no livro convencional, o imenso pergaminho digital vai enrolando várias vozes, que se deitam umas sobre as outras na descida e na subida do cursor. Engendra-se o novelo heterogêneo de sentidos, sujeitos e arquivos, que se justapõem em um patchwork de fundura e largueza imensas, fazendo tagarelar ditos tantos. Algo como pintar na tela o que só é "encontrável em outro lugar", na voz e na memória do outro. Ou então, criar um "novo" lugar de conexões, um outro nó no emaranhado de sentidos já dados, estabelecendo um lugar originário, ponto de partida e sítio que, logo após a sua fecundação, dará abrigo a várias vozes, 
como é o caso do blog do qual falarei na próxima sessão. Sobre isso, Oliveira (2004: 206/207) afirma:

\begin{abstract}
"O ambiente da Internet é o espaço dessas múltiplas culturas, desses múltiplos 'eus', que se entrecruzam e redimensionam a questão do que é ser pós-moderno. o sujeito multiplica-se, é sempre um duplo ou múltiplo e, ao mesmo tempo, descentrado, não tendo mais certeza da sua singularidade. Isso tudo provoca efeitos sobre as identidades, tornando-as pluralizantes e quase sempre confusas (...) sujeito como um ser heterogêneo, cindido, atravessado pelo inconsciente, babitado por desejos recalcados que irrompem via simbólico, pela linguagem (...) Podemos pensar que o sujeito, ao buscar sua singularidade (...) depara-se com lacunas, desvios, ou seja, com a incompletude (...) Isso tudo provoca a busca de sua voz singular e das vozes dos outros, de sua presença e da presença de outros, um processo constante de idas e de voltas para encontrar a completude, a unicidade."
\end{abstract}

E certamente, ao clicar no link em que a voz de outro(s) está fixada, o sujeito desvia-se do que realmente buscava na primeira entrada sua na rede. Clicando, ele desloca-se por entre-meios de páginas, links e ícones que o endereçam a outros sítios, a tantas teias intertextuais nas quais se perde ou se acha. Ao ler (e interpretar, quem sabe?) a página eletrônica, o sujeito-navegador tem simultaneamente uma cartografia com várias rotas de acesso, múltiplas entradas para pisar na voz do outro, diversas janelas para abrir arquivos que, como eu disse anteriormente, já foram previamente escolhidos. No infomar, cada link é uma rede em si mesmo, como se por analogia cada onda do mar pudesse encerrar nela mesma um outro mar de ondas à parte. Assim, gestos de leitura e a escrita recebem nova configuração.

Em relação ao primeiro, a discussão posta até aqui tem relação com o processo histórico de "divisão social do trabalho da leitura", que Pêcheux (1982:58) acredita inscrever-se "numa relação de dominação política: a alguns, o direito de produzir leituras originais, logo 'interpretações', constitutindo, ao mesmo tempo, atos políticos (sustentando ou afrontando o poder local); a outros, a tarefa subalterna de preparar e de sustentar, pelos gestos anônimos do tratamento 'literal' dos documentos, as ditas 'interpretaçôes". Pergunto: até que ponto o sujeitonavegador lê e interpreta sentidos na rede, produzindo atos originais de atribuição de sentidos e, portanto, rompendo com a cadeia da leitura literal ou parafrástica? Não seria o seu gorjeio de leitura apenas o ato repetitório de clicar e deslocar-se por pontos de deriva e dispersão sem a percepção do ato político de estar na rede? Sobre isso, Maldidier (2003:88) faz a seguinte colocação: 
“(...) a tradicional 'divisão social do trabalho da leitura' que opõe os 'ruídos' da leitura literal aos que gozam do privilégio da interpretação, de tal modo que os primeiros são condenados à 'letra' enquanto os segundos acedem ao sentido. Aí estão duas leituras, mas também duas culturas, tradicionalmente designadas como 'científicas' e 'literárias' (...) Para Michel Pêcheux, neste início dos anos 80, a dicotomia 'científico' vs 'literário' está precisamente em vias de se reorganizar, aprofundando-se... A informática pode representar a mais grave das ameaças... a menos que a utilizemos como uma arma para defender os espaços não fechados dos sentidos".

A aventura teórica de compreender o arquivo eletrônico em sua instância ideológica, a rede como emaranhado de vozes e o gesto de escrita e leitura como prática social autorizada para alguns e interditada para outros não me parece empreitada fácil, mas somente possível se a tomarmos dentro da dimensão do político, como Maldidier (2003: 94) o faz: "A informática não representava para Michel Pêcheux um setor 'ao lado', uma 'curiosidade'. O recurso à informática se inscrevia no interior de um pensamento político. Era necessário se instalar no centro mesmo do fluxo, não para o conter, mas para aí preservar espaços de interrogação, para aí desfazer o fechamento dos sentidos"

E para "defender os espaços não fechados dos sentidos", a perspectiva discursiva me parece um terreno alentador, se se observar que, na rede, há a seguinte contradição: de um lado, aqueles que se deslocam no entremeio das vozes já-lá, entram e saem dos links como se passeassem em um shopping planetário, olhando mercadorias-informações novas, lançamentos da estação, zapeando atrações diferentes, folheando promoções de produtos e, de outro, aqueles que são falados e nomeados nos sites, sem nunca terem acessado as páginas eletrônicas em que são narrativizados (Romão 2004).

Existem, por fim, aqueles que se autorizam a instalar um endereço fixo, talvez a moradia para sua voz, criando diários íntimos na rede e expondo publicamente parte de sua vida privada. No branco da tela, registros, flashes, indagações e cenas de uma representação cotidiana e, de novo, "a imagem do que apenas noutro lugar é encontrável".

\section{Nas tramas do blog, a heterogeneidade de vozes}

Blog, página pessoal, diário íntimo na internet, link com comentário, home-page pessoal on-line, página disposta em ordem cronológica e espaço de discussão (Araújo 2005): várias maneiras de nomear o texto que 
registra fatos e impressões do cotidiano, documentando o irrisório, circunstancial e episódico do cotidiano. Diante da variedade de denominações e blogs, trabalharei aqui com a noção de diário íntimo, pontuando de início que o caderninho do passado guardado a sete chaves, envolto por marcas muito pessoais como laço de fita, fotografia, folha seca, cartão postal etc, ganha nova configuração. O segredo era preservado apenas pelo/ para o diarista, não se estendia ao espaço do(s) outro(s), compunha o cenário de cochicho solitário, confidência murmurada, confissão marcada por um momento que, em geral, não se queria ver partilhar na esfera pública. Sobre isso, Saramago (1998:205) assim define o diário:

"este registro de idéias domésticas, de sentimentos quotidianos, de circunstâncias médias e pequenas, não ganhe em importância ao diário de um colegial, no tempo em que os colegiais escreviam diários. Eu próprio me pergunto por que me terá dado para este exercício um tanto complacente. Ou talvez não o seja, talvez eu acredite que assim retenbo o tempo, que o faço passar mais devagar só porque vou descrevendo algo do que nele acontece."

Talvez o tempo fotografado, supostamente inscrito nos relatos diários e guardado, seja no papel ou na tela, seja a grande questão nessa discursividade. Dia a dia desfolhar os dados miúdos da vida, atribuindo-lhes grau de maior ou menor relevância, apagando certos fatos em prol da narrativa de outros. A lente de aumento, que está sempre focada na esfera do privado, particular e reservado, recorta alguns temas a serem narrados. Aí, também, a ideologia (Pêcheux 1969) funciona de modo a parecer evidente e natural que o sujeito disponibilize uma informação sobre sua vida e interdite outras, desviando-se de sentidos indesejáveis, proibidos e impossíveis de dizer na posição determinada pela ideologia.

$\mathrm{Na}$ rede eletrônica, o diário íntimo na rede desfronteiriza o que é privado e público e essas duas esferas passam a se imbricar de modo inseparável, pois a voz do blogista é atravessada pela voz de inúmeros internautas colaboradores Eles enviam post (comentários) para a página pessoal, remetem fotografias, fazem interferências de vários modos, colam links dentro do blog e enredam-se nele a todo instante, inscrevendo uma mixagem de vozes indiciária de uma heterogeneidade constitutiva e, sobretudo, mostrada (Aulthier-Revuz 1990). Tal movimento redimensiona a própria essência desse "gênero textual" já que ele, diferentemente do diário impresso cujo único interlocutor-testemunha é o autor, alimenta-se dos que visitam 
e acessam a página, dos que por ali passaram depositando seus vestígios de interferência.

O diarista, ao alocar seu blog em uma região de sentidos na rede e ao escolher um tema, o faz pensando no interlocutor, isto é, nesse(s) outro(s) que irão tomar o fio do seu discurso e carregá-lo adiante. Esse espelhamento de vozes, manifesto em tempo real, é algo novo, se pensarmos que diversos navegadores-leitores se cruzam diariamente, tagarelam sobre fatos pessoais, enviam fotografias e imagens e fazem mover uma teia intertextual de ditos e silêncios. Vale aqui acrescentar que o blog se sustenta dessa retroalimentação e se faz notório e reconhecido na proporção em que o número de visitantes cresce. Várias vozes entram no blog para comentar (comments) dados pessoais, enviar contribuições, dicas, orientações (post), endereçar fotografias, polemizar sobre certo assunto e provocar o riso por meio de brincadeiras. Esse jogo de movimentos é o que torna a página atraente, criativa e marcada pela disputa, tensão ou graça (inexistente no antigo diário, no qual se cria o efeito de monofonia), posto que a fronteira entre as vozes se camufla sob o efeito de a continuidade interminável de dizeres sobre certa pessoa, questão, tema etc.

Sob o ponto de vista das características, o blog não é marcado apenas pela dissolução do público e privado, visto que Schittine (2004:14-15) chama a atenção para outras diferenças:

"Paralelamente, é importante observar como antigas questões relativas ao diário no papel ganham uma nova perspectiva quando se trata do diário virtual, embora permaneçam as mesmas. Daí a importância de desenvolver certos pontos: a memória (imortalidade e permanência), o segredo (o contar ou não a intimidade a um desconbecido), a tensão entre o espaço público e privado (que vai aumentar com a passagem para a internet) e a relação com o romance (fiç̧ão) e com o jornalismo (a observaşão dos fatos). Tudo isso tentando não perder de vista quem é esse autor, seus desejos, anseios e o que pretende com a abertura do terreno intimo para o público."

Os elementos acima indicam a complexidade do gênero e a necessidade de o sujeito-diarista ser lido na sua intimidade, mostrando-se e exibindo-se nessa jaula eletrônica, a partir dos vestígios de seus textos e relatos, na mesma medida em que isso cria um interesse por vasculhar a intimidade alheia, inscrevendo-se aí uma outra ordem de dizer de vários outros emparelhados no espelho do exibicionista, que se amparam e se nutrem nessa "rede de segredos". Sobre isso, Schittine (2004:20-21) afirma: 
"A partir daí, se formam pequenos grupos que dividem segredos entre si, formando 'redes de segredos', com alguns nós em comum. Elas funcionam como uma espécie de confrarias de indivíduos que guardam entre si uma informação sigilosa (...) A rede se transforma em uma pequena província onde grupos de pessoas afins guardam confidências entre si (...) O diarista virtual determina quem pode se aproximar de seus segredos mais intimos e quem não deve suspeitar deles através de senhas, do texto cifrado e do acesso restrito ao blog. É ele que estabelece o quanto o leitor comum deve saber de sua vida particular e o que deve ser mantido em sigilo".

Vale registrar, a título de passagem, que essa desfronteirização do que é público e privado ficou emblemática no caso do passeio de avião do filho do presidente Lula com seus amigos, no ano passado. Apenas uma foto, publicada na página pessoal de um jovem, foi o suficiente para trazer à baila a discussão sobre o uso do patrimônio público para fins pessoais, para comprometer a imagem do poder federal e para tornar pública uma viagem aparentemente descontraída e sem importância. $\mathrm{O}$ modo como tal segredo foi desvelado pontua que o tamanho dessa rede de segredos não é pequeno. Em uma busca realizada no Google, no dia 10/02/2005, constatei que existem 1.890.000 blogs em Língua Portuguesa a serem acessados.

Há, inclusive, páginas que didatizam como usar o blog: "Dicas para blog", "Como criar seu blog", "Regras de etiqueta para blogs", "Blogalize", "Diretórios de blogs" "Listblog", dentre outras. Os eixos temáticos se dividem em categorias como as que se seguem: culinária, adulto, animais de estimação, brasileiros no exterior, fotoblog, humor, natureza, poesia e reflexão, pessoal e estilos de vida, política e sociedade, variedades, universo feminino, religião, música, comunicação, esoterismo, artes etc. Há blogs alimentados a quatro e seis mãos e compartilhados entre amigas; há jornalistas que mantêm uma página mais livre em que escrevem tudo aquilo que deixam silenciar nas redações jornalísticas; há grupos de direita e neo-nazistas que vociferam sentidos de extermínio; há movimentos de mulheres com temas pertinentes à maternidade, trabalho doméstico, saúde feminina e carreira; há poetas e escritores com sua produção literária e textos inéditos não inclusos no mercado editorial formal; há minorias sexuais implantando bandeiras de luta; há brasileiros que de várias partes do mundo despejam ali uma conexão de saudade com os familiares, amigos, terra natal; há relatos jornalísticos não autorizados pelas grandes corporações. Enfim, uma profusão tão grande de temas sustenta o imaginário de que tudo e todos estão on-line e de que é possível abarcar qualquer assunto ou proposta no ciber- 
espaço. De novo, apresento minha ressalva diante dessa posição de acessibilidade infinita, visto que os blogs apenas materializam o quanto da memória foi selecionado para estar ali. Também vale pontuar que o sujeito-navegador apenas chega a tais blogs se tiver acesso à memória e ao arquivo, se souber fazer a busca, se conhecer os meandros da navegação para atracar em links de seu interesse. Do contrário, naufrágio. Portanto, a memória é superfície para a constituição do arquivo e do internauta.

Voltando à profusão de temas, ela também indicia que qualquer dado merece relevância a ponto de ser arquivado e tem estatuto de local a ser visitado e remexido, ainda que a identidade e a origem do blogista seja completamente apagada. Conforme Komesu (2004: 116-117), é preciso anotar que:

"Como os blogs são produzidos para serem veiculados pela Internet, isto é, na trama dos computadores interligados no mundo todo, a referencia ao lugar de onde se enuncia parece irrelevante, a não ser quando faz parte da composição das histórias. Da perspectiva de um apagamento da referência do lugar no cabeçalho, pode-se depreender uma certa estratégia de sigilo sobre o espaço da enunciação empírico para a construção de um outro espaço, aquele no qual o escrevente imagina escrever o que bem entender. A ausência dessa referência explícita indicia o momento em que o escrevente 'sai' do lugar físico para se constituir num outro espaço, na virtualidade (...)".

Assim, com as circunstâncias da enunciação ocultas e sabotadas, fica parecendo que tudo está disponível na rede virtual e que o universo inteiro está na tela e on-line, naturalmente ofertado para o aldeão global, que pode estar (ou ser) aqui ou acolá como se isso pouco importasse. De novo, vale ressaltar que esse mito da acessibilidade infinita no ciberespaço merece des-construção, pois o que se mostra na internet é uma soma de arquivos eletrônicos que foram recortados, selecionados e manipulados anteriormente a sua exposição, que instalam, no espaço do dizível, sentidos de universalidade. É como se tudo e todos estivessem lá, ainda que vindos de lugar nenhum; é como se houvesse uma equivalência natural e/ ou direta entre esse ciberespaço construído e os atos de linguagem que o constituem; enfim, é como se a injunção ideológica do dizer e do lincar não existisse e, por fim, é como se os sentidos na/da textualidade eletrônica não fossem "encontráveis em outro lugar". 


\section{Considerações sobre lugar da autoria na rede eletrônica}

Até aqui tive interesse de definir o arquivo eletrônico, o papel da memória na rede, a topografia multilinear dos acessos, o sujeito-navegador e a injunção ideológica de sua escritura. O blog, como baú de lembranças materializadas virtualmente, teve suas características e particularidades apresentadas, especialmente marcantes pela dissolução da esfera do privado e do público, pela heterogeneidade, pela interatividade e pela vastidão de temáticas. Por isso, vale reafirmar que, na canastrinha eletrônica, cabe apenas quanto a memória e a ideologia deixaram falar (ou calar) e, sobretudo, que não é porque se escreve muito em quantidade de linhas e se lê muito em volume de links que os internautas tornaram-se autores da noite para o dia, mesmo reconhecendo que, ao se conectar, lê-se muito e usa-se a ferramenta da escrita para desenvolver a cartografia de navegação. Entretanto, isso não quer dizer que o sujeito ocupe, como conseqüência automática, a posição de autor, posição esta aqui compreendida na esteira da Análise do Discurso.

Entendo autoria como o movimento discursivo do sujeito para assumir uma posição de responsabilidade pelo seu dizer (Pacífico 2002), preenchendo espaços lacunares com estratégias de contenção dos sentidos e de amarração do seu dizer na ancoragem de outros dizeres e na rede da memória. Tal manobra não é fruto da vontade do indivíduo nem do querer das suas intenções, mas fruto da tensão existente entre a memória do dizer e a ideologia, que torna alguns sentidos naturais e evidentes para o sujeito em determinada posição, apagando ou sabotando completamente outras formas de dizer.

Assim, o princípio da autoria tem sua materialidade lingüística na injunção ideológica, que interpela o sujeito em um ponto da rede da memória e não em outro, fazendo-o buscar o efeito de unidade para o seu dizer, ainda que eles - dizer e efeito - sejam imaginários. Essa posição, em que o sujeito tenta controlar a deriva e os pontos de fuga dos sentidos e busca amarrar o fio do discurso, cria para o seu dizer um fecho imaginário com começo, meio e fim. Sobre isso, Tfouni (2001:82/83) afirma que:

"O autor é uma posição do sujeito a partir da qual ele consegue estruturar seu discurso (oral ou escrito) de acordo com um princípio organizador contraditório, porém necessário, visto que existe, no processo de produção de um texto, um movimento de deriva e dispersão de sentidos 
inevitável, que o autor precisa 'controlar' (...) o sujeito ocupa a posição de autor quando retroage sobre o processo de produção dos sentidos, procurando 'amarrar' a dispersão que está sempre virtualmente se instalando, devido à equivocidade da língua".

Vista dessa forma, para colocar-se na posição de autor, o sujeito precisa ter domínio (ainda que imaginariamente) dos sentidos que supõe produzir, fazendo movimentos de referenciação, antecipação e retroação, não deixando o sentido ir para qualquer lugar nem ser qualquer um. É justamente esse movimento de contingência, contenção e amarração que caracteriza os gestos de autoria e que dialoga com a noção de arquivo e memória, visto que, para controlar o fio do discurso, o sujeito necessita de referências de outros discursos já dados sobre o assunto; precisa passear por várias regiões da memória, entrelaçando à sua voz essas superfícies e retalhos discursivos, depositários de sentidos do que "só é encontrável em outro lugar". Autoria implica o sujeito ter acesso ao arquivo, definido por Pêcheux (1982) como campo de documentos sobre uma questão; implica uma situação de tensão grávida de polêmica, disputa e possibilidades; e implica, por fim, que a luta de vozes, sentidos, posições deixe suas pistas cravadas na superfície lingüística, distanciando-se de um mero exercício repetitório e parafrástico.

Tais noções orientadoras da discussão até aqui se somam a novos questionamentos: será que o acesso à superfície dos arquivos eletrônicos, materializados na rede, cria novas condições materiais para que o sujeito assuma a posição-autor? O espaço volátil da Internet e da textualidade eletrônica inscreveria uma nova discursividade e outras proposituras para a autoria? Os blogs sinalizam um espaço generoso para estudar tais movimentos? Diante dessas perguntas e observando o curso da fugacidade da discursividade eletrônica, não vocalizo certezas. Tantas perguntas, tantos sentidos em curso, que só se revelam na materialidade lingüística, no dis-curso em movimento.

Embrenho-me no estudo de dois blogs para, se não encontrar respostas, ao menos rastrear, na materialidade lingüística, alguns passos do sujeito navegador e de seus movimentos de autoria. O primeiro blog interpretado chama-se Mexidão ${ }^{1}$ e é encontrável no endereço www.mexidão.blogse.com.br, tem como responsável a jornalista Tatiana Coutinho, mineira de

\footnotetext{
1 Acessado muitas vezes durante os meses de fevereiro e março de 2005.
} 
Belo Horizonte. O blog foi alimentado até o final de 2004 com periodicidade diária e apresenta vários comentários (post) de internautas indicando ter sido visitado regularmente. Há frames do lado esquerdo da página, indicando uma série de arquivos dos meses anteriores, manchetes da Folha de S.Paulo e do Estado de S.Paulo, indicadores da bolsa, dólar, o tempo em Belo Horizonte e um mini-mural com recados de amigos, afetuosos nos comentários e bilhetinhos, dirigidos à dona da página. O ícone da página é um microfone com pé suspenso, peça usada nos programas de rádio, indicando ser esse um espaço de amplificação de voz e exposição de vários dizeres vindos de diferentes navegadores. O nome do blog, Mexidão, marca o lugar do entrelaçamento de discursos, sujeitos e sentidos, visto que a heterogeneidade dos ditos de vários visitantes irá se unir aos ditos da página, inscrevendo um dizer heterogêneo que, em si mesmo, é mexidão. No centro da página, há um grande frame com recursos verbais e não-verbais, seguidos de um link indicativo dos comentários. Recortei uma seqüência de dados do mês de agosto para interpretar o funcionamento discursivo do blog.

\section{A teoria de Darwin} A Evoluçăo do "Homi"

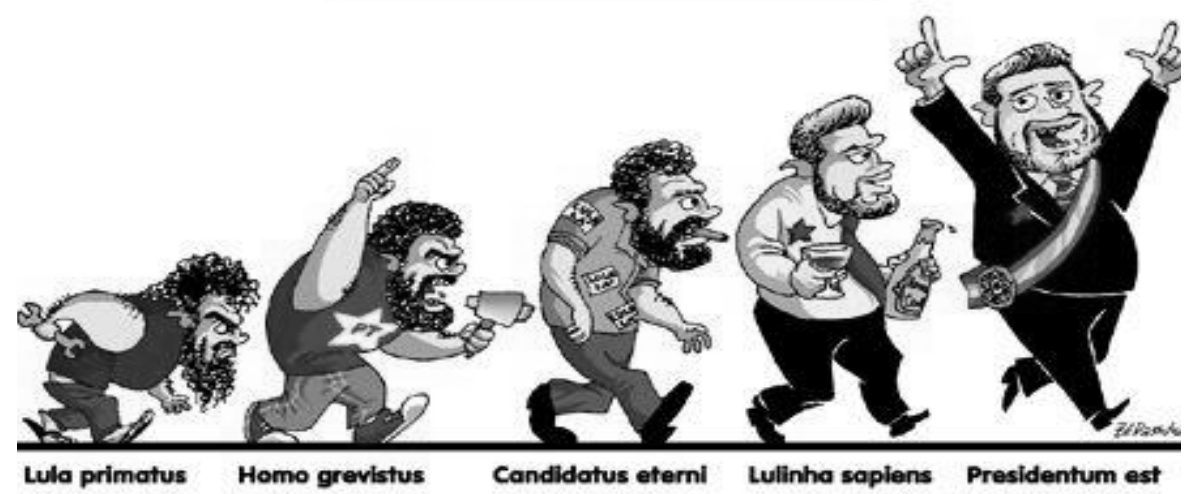




\section{Enquete sobre o Conselho Federal de Jornalismo}

Os deputados querem saber a opinião do povo a respeito da criação do Conselho Federal de Jornalismo. No site da Câmara Federal foi lançada uma enquete para colher as opiniões.

Vamos votar!

Clique aqui para entrar na página da Câmara e participar da enquete

Só para constar: eu sou contra!

Recadinho:

Amiguinhos e leitores do Mexidão,

Estou super sem tempo. Por isso ainda não respondi aos comentários, nem visitei os blogs dos quais sou super fã. Prometo, em breve, corriger este erro.

Tatiana Coutinho | Comentários (4)

$4 / 08 / 2004$

\section{Olimpíadas}

Foto publicada no jornal Estado de Minas

Nada contra o Brasil (afinal, o melhor do país são os brasileiros), mas a Olimpíada aqui não chegaria, nem perto, do que acontece em Atenas.

Já imaginaram como seria a abertura no Rio de Janeiro??? Um bando de mulheres sambando, peladas, ao som do pandeiro. Ao invés do Maracanã, a festa olímpica poderia acontecer na Marquês de Sapucaí. Minha chefe ainda completou a premonição da festa da "união dos povos" no território brasileiro com a grande sacada: perfomances prá lá de tupiniquins, embaladas pela folia baiana, acompanhadas do repertório como a "Boquinha na Garrafa".

$\mathrm{O}$ amigo Tom fechou com chave de ouro. "Aqui a gente só sabe tratar de sexo", disse. Pelo menos isso nós fazemos bem!!! 
$4 / 08 / 2004$

\section{Torcida para Chavez}

Não é à toa que sou fã de Fernando Moraes e Gabriel Garcia Marquez. Os dois estão apoiando Hugo Chavez, que terá seu futuro decidido na Venezuela amanhã.

Bons motivos para Chavez no poder: um sistema falido está condenado ao fracasso. Vejam o caso do Brasil. O PT chegou ao governo, mas teve que se submeter ao vício do sistema brasileiro. Até agora, ocorreram poucas mudanças.

Tatiana Coutinho | Comentários (2)

Essa seqüência, aparentemente desarticulada de textos e dispersiva de discursos, vai produzir uma tessitura textual de links, relatos, notícias, comentários que reclamam o tempo todo o retorno a uma voz já dita na página ou fora dela, melhor dizendo, ao arquivo e à memória. O candidato Lula, o projeto na Câmara dos deputados, as Olimpíadas e a Torcida pelo Chavez materializam lugares já-dados, onde o sujeito se ancora para enunciar e, assim, atualizar discursos sobre a realidade. Sem dar atenção aos relatos restritos ao seu mundo pessoal, como por exemplo, meu cachorro, minha casa, minhas viagens, meus amigos e tantos outros meus, o que é comum nos blogs, a "dona" do blog ocupa a posição que fala como brasileira, cidadã, eleitora, participante da vida política de seu país que compartilha, não seus dramas e sentimentos pessoais, mas seus posicionamentos. Ao final de cada notícia ou imagem disponibilizada pela jornalista, os comentários podem ser acessados.

A aparente "desordem" ou fragmentação da página se apóia no fato de que o sujeito-navegador pode mover-se ao longo da página do primeiro ao último texto com apenas um clique, pode desviar-se do frame central para outros links e perder-se (ou achar-se) em sucessivos acessamentos e, sobretudo, pode deslocar-se sem a cadeira linear estruturada na/pela escrita e na/pela leitura convencionais: uma linha após a outra, uma página que se segue à outra, um espaço preenchido após o outro sempre em seqüência. Tal topografia fragmentada em múltiplas direções e com múltiplas janelas 
prontas a serem abertas, indica que, a cada texto ou imagem seguidos de comentários, um livro se escreve e se encerra em uma teia menor do hipertexto. O assunto Lula, por exemplo, abre-se e fecha-se em si, inscrevendo uma discursividade heterogênea e não necessariamente marcada pelo fecho imaginário, pressuposto da autoria com início, meio e fim, mas fica espalhado, fragmentado como estilhaços do assunto Lula lançados em várias direções.

A seguir, vou analisar apenas a teia construída em torno do cartum " $A$ evolução do homi" e os comentários relacionados a ele. Não é possível assegurar com precisão quem é o artista criador da imagem, mas aponto que, no ato de retomada da voz desse outro-cartunista, marca-se uma heterogeneidade mostrada, visto que em lugar das suas próprias palavras no lugar de jornalista e de dona do blog, há marcação da retomada de algo já dito em outro lugar. Ao fazê-lo, o sujeito materializa a formulação explicativa " $A$ teoria de Darwin”, produzindo os efeitos de esclarecimento sobre a evolução de Lula (efeitos estes implícitos no cartum) e promovendo o gancho explícito de deslocamento do tema da biologia para a política.

Repousa, na zona do interdiscurso, uma teoria sobre a espécie humana, que, nesse caso, é atualizada no intradiscurso, passa a ser mote para o risível, a chacota e a gozação e também faz falar a escala evolutiva do "bomi" e não do homem. Considerando que o sujeito interpelado pela ideologia sempre recorta uma rede da memória para significar (-se), podemos dizer que apenas um aspecto da teoria darwinista foi anotado: aquele que segmenta mudanças do macaco ao homem. Também faz sentido afirmar que os quadros imagéticos contam uma história de vida específica, ou seja, instalam uma narrativa, que também segmenta etapas de evolução do líder sindical à presidência da República.

A crítica ao Lula no lugar de presidente ganha relevo lingüístico na designação "bomi", indício da oralidade e da quebra da norma culta, que, na formação ideológica dominante, é atribuído ao vocabulário dos que estudaram pouco, dos que estão embrutecidos pela falta de acesso à cultura, dos que se apresentam diminuídos por disporem apenas das ferramentas do trabalho braçal. Todos esses sentidos pejorativos em relação ao uso social do termo "homi" materializam-se afetados por condições de produção de uma luta ideológica de poder, entre os que têm e os que não têm acesso ao saber institucionalizado pela escola. Essa interpretação só é possível pela memória do dizer, o já-lá que sustenta o sentido de zombaria em relação à 
variante lingüística usada pelo presidente e que faz emergir aqui, ainda que sob o modo da corruptela, o latim, língua da ciência.

Em diálogo com isso, combina bem a coluna curva e a aparência amacacada do "Lula primatus", ainda no estágio da chave de fenda. Chama a atenção a ascensão desse momento ao "Presidentum est" com o andar primata se transmutando em homem ereto. Assim, retorna a memória já dita sobre a ancestralidade biológica do homem e seu parentesco com o macaco. No começo curvo, quadrúpede, primata peludo e, nesse cartum, curvado à frente, submisso à condição de metalúrgico com a ferramenta na mão, os cabelos e barba apontados para o chão e os ombros sustentadores do peso de sua condição operária. À medida que o tempo passa, vai se delineando uma construção imaginária para o político "bomi”, pontuada por novos atributos, a saber, "grevistus", "eterni", "sapiens", como a indicar que a "espécie" Lula passou por mudanças de fases e abandonou os rudimentares objetos da fábrica para lançar mão de outros recursos ao longo de sua biografia. Aparecem a estrela do PT, o megafone e o braço erguido alinhado ao corpo mais definido em postura de enfrentamento. Refere-se aqui ao período de liderança sindical, em que as greves de metalúrgicos sacudiram o ABC paulista e - por que não dizê-lo?- momento em que o então operário "começou a dizer não" e tomar a linguagem como arma de combate.

Na etapa seguinte da evolução, vê-se a entrada de Lula na disputa presidencial, primeiro como candidato eterno em sua aparência de revolucionário, fumando um charuto (supostamente cubano), de modo a indicar um alinhamento ao regime castrista ou de esquerda. Gradativamente, novos adereços vão surgindo, são incorporados ao visual do candidato, emprestados do imaginário de prestígio que circunda a elite nacional. Gravata, champagne ou qualquer outra bebida que mereça taça, contenção de gestos e a polidez no andar e no grito silenciado como passaporte para a civilização, para a evolutiva carreira de político e virtual conquista da presidência. O diminutivo "Lulinha" marca efeitos de suavidade e miniaturização do perigo da esquerda e da contestação, que agora aparecem deslocados pela aparência física de Lula, visto que ele não ameaça mais, não reivindica nem assusta, minimizada a rebeldia e o desejo de modificação das relações produtivas. Ou seja, eis que Lula está pronto para ser eleito.

Considerando que o sujeito é sempre interpelado em sujeito pela ideologia, também podemos ler o cartum pelo seu avesso, ou melhor,é possível interpretar que, mesmo buscando efeito de riso e deboche, o sujeito repro- 
duz efeitos do sentido dominante de que ser de esquerda é não estar modernizado e nem atualizado frente às demandas dos novos tempos, de que um bom político é a medida do seu diálogo com a elite e de que o estado "primatus,grevistus" remetem à condição primitiva e animalesca da figura de um político.

Registro que essa interpretação reclama que o sujeito tenha acesso ao arquivo que constituem sentidos sobre o candidato Lula, sua biografia, as condições de produção em que seus dizeres ganharam relevância como líder sindical e articulador das massas operárias, as lutas políticas travadas contra a ditadura, as campanhas presidenciais e a estratégia política para chegar à presidência. Também remete o leitor ao conceito darwinista de que há uma cadeia de alterações fisico-biológicas capazes de documentar a história do homem (e do "bomi") na terra. Vale anotar que a frase inicial " $A$ teoria de Darwin" e o cartum se somam como se tivessem escritas pelo mesmo autor, quando na verdade não foram. Tal zona fronteiriça de vozes entremeadas, justapostas e colocadas em cadeia como continuidade é a marca da textualidade eletrônica, da inscrição social do sujeito-navegador e da autoria na rede. A mixagem é tamanha que as pegadas das vozes particulares se dissolvem. Em vista disso, mobilizar o conceito de memória e arquivo, afetados pela ideologia e crivados pela heterogeneidade, me parece fundamental para compreender o sujeito e o sentido na malha digital, em geral, e no blog, em particular.

Logo abaixo do nome da autora, nove comentários são disponibilizados com campos fixos preenchidos eletronicamente. A formatação na rede tenta conter a dispersão que lhe é própria, normatizando formulários, fichas, estruturas de contenção, nesse caso, são mantidos quatro espaços: nome do autor do post, data da postagem do comentário, blog de origem (quando existe) e a própria mensagem. Clicando em cima do nome de quem enviou a mensagem, o aplicativo do outlook é aberto e um mail pode ser enviado, isso indica que a teia de diálogos é imensa, estabelecida pelas conexões possíveis entre os visitantes do blog com a dona da página, entre os blogistas com os visitantes e entre os visitantes entre si. Registros de saudade, cumprimentos, pedidos de retorno, bilhetinhos com exclamações e interrogações se espalham um embaixo do outro, desfigurando a acidez sarcástica do cartum e silenciando qualquer posicionamento sobre ele. O exercício de interpretação do estímulo visual e textual disponibilizado como mote não foi feito, exceto em algumas mensagens em que a evolução do "bomi" foi implicitamente referenciada. 
Data de Envio: 16/9/2004 17:57:00

Blog:

Tati, vc nos abandonou de vez??? Estou com saudades dos tempos em que o Mexidão era atualizado com frequência!! Beijos amiga! E volta logo!

Data de Envio: 14/9/2004 02:32:00

Blog: Patolino

Oi gatíssima! Cê sumiu também, né? Buááááá..... =( Tô com saudade, mande notícias. Beijos

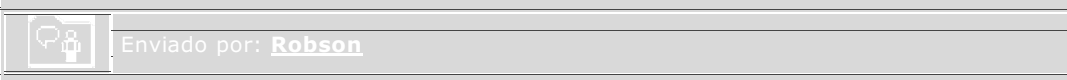

Data de Envio: 12/9/2004 23:13:00

Blog: www.robsoneblues.blog-se.com.br

Para uma semana dura como será a minha, conto e torço para mais um texto no Mexidão. Afinal, blogs legais tornam a vida mais suportável (tô exagerando?)

Data de Envio: 9/9/2004 13:25:00

Blog: www.mineirissima.blog-se.com.br

Tati : visito "regularmente" o seu blog - mexidão gosto bastante ....... Vovó (não sou coruja, viu?)

Data de Envio: 8/9/2004 22:34:00

Blog: www.soltandopipa.blog-se.com.br

Oi!!!

Data de Envio: 7/9/2004 10:12:00

Blog:

TaTi - "Vim, vi e roubei!" ...É o que queria dizer.

Concordo contigo Robson!

Denvio: 6/9/2004 19:13:00

Blog: www.robsoneblues.blog-se.com.br

Tati, tenho minhas ressalvas a este governo, mas reconheço que se o Lula ficasse no estilo $A B C$, jamais chegaria lá. O lado positivo é que mesmo sendo um pinguço, ele não bota supositório de coca, igula ao Colorido e tb não é um preguiça-lesa como FFHHCC, que não queria nada com o basquete e jogou todas as reformas para o L. resolver. 


\begin{tabular}{l} 
Data de Envio: 6/9/2004 00:32:00 \\
\hline Blog: \\
\hline Vi, vi e roubei!" \\
\hline \hline \\
\hline Data de Envio: 4/9/2004 00:05:00 \\
\hline Blog: www.mineirissima.blog-se.com.br \\
\hline Tatiana..........Achei genial....legal demais!!!!!!!!!!!!!!!! \\
\hline
\end{tabular}

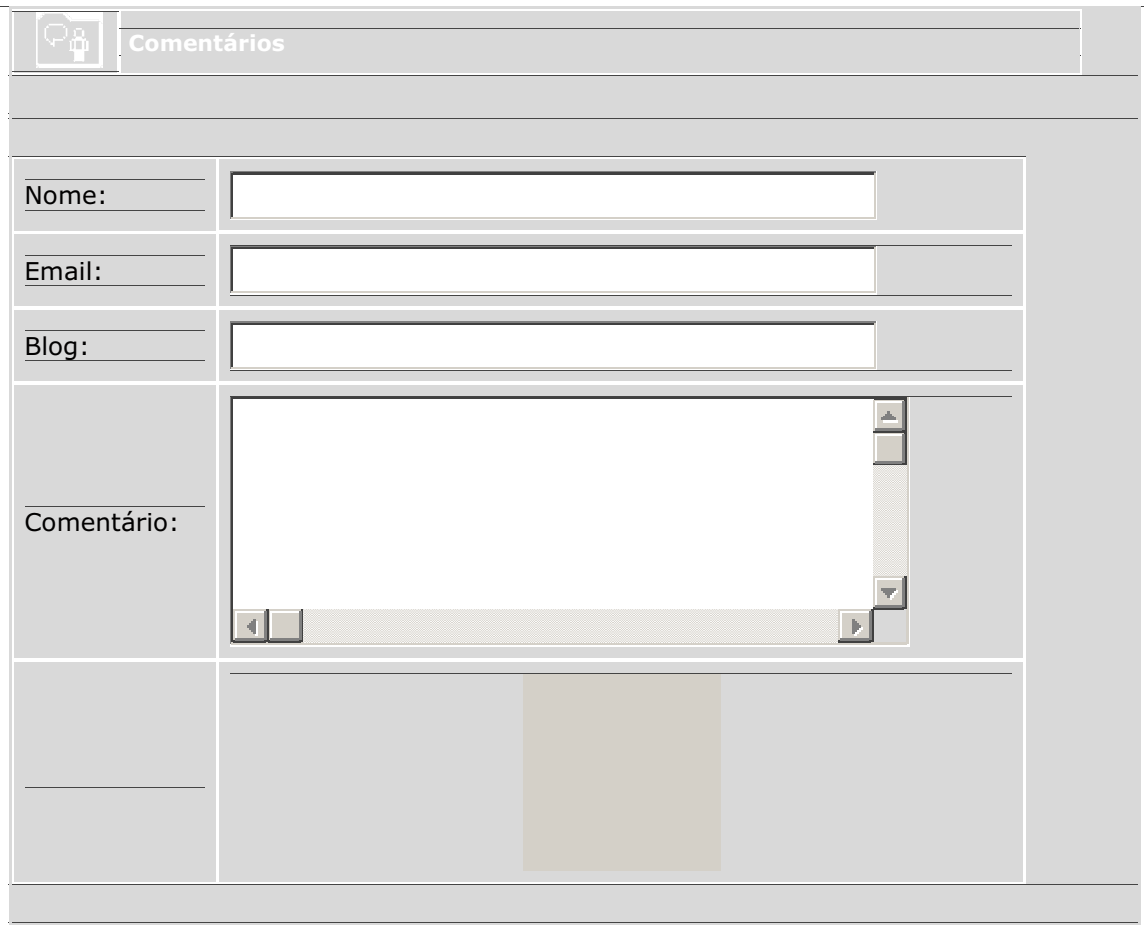

A formulação "Vim, vi e roubei" instala a retomada da voz de um grande imperador diante dos desafios de conquista territorial, "Vim, vi e venci". A nova construção de sentidos entre "venci" e "roubei" fica implícita e apenas interpretável para aqueles que têm acesso ao arquivo, tal qual Pêcheux propõe. De novo a memória faz funcionar sentidos, sustentando deslocamentos, rupturas e manutenções, no caso, é ela que disponibiliza a senha 
para que o leitor costure os efeitos entre "Presidentum est", alegria da vitória e o ato de roubar. Roubar não dinheiro no sentido restrito, mas o roubo que Lula impôs a si mesmo, o roubo do projeto político petista, das reformas de base, da reordenação do país frente ao capital internacional e da representação de um governo de esquerda, voltado para demandas sociais como a reforma agrária, por exemplo. Roubar não o dinheiro dos cofres públicos, mas as cédulas de credibilidade conquistadas, a duras penas, em sua biografia de trabalhador e tecida no bojo de lutas políticas caudatárias.

Para compreender a tessitura textual entre título inicial, cartum e as mensagens, é preciso voltar à voz do outro, recuperar o fio do discurso jádito, remontar as peças discursivas do quebra-cabeça disponibilizado, enfrentando momentos de deriva e dispersão dos sentidos como se viu acima. A "saudade", o "buáááá", o "oi", o "gosto bastante" vão se emendando aos momentos em que o lugar da autoria não é materializado por movimentos de amarração e retroação. A seqüência que se segue é prova disso: "Tati, tenho minhas ressalvas a este governo, mas reconbeço que se o Lula ficasse no estilo $A B C$, jamais chegaria lá. O lado positivo é que mesmo sendo um pinguço, ele não bota supositório de coca, igual ao Colorido e tb não é um preguiça-lesa como FFHHCC, que não queria nada com o basquete e jogou todas as reformas para o L. resolver".

$\mathrm{O}$ que eu disse até aqui indica que talvez as marcas de heterogeneidade e do arquivo na discursividade eletrônica promovam uma quebra no conceito de autoria, tal qual o conhecemos quando aplicado a textos científicos, literários, didáticos ou relatos orais. O postulado teórico já dado até aqui não pode ser adaptado para as novas condições de produção, posto que não cabe na forma da rede, em que o suporte e o que nele se (ins)/ escreve não há princípio nem fim, não apresenta um centro controlador, não exige mecanismos de ancoragem para que a navegação continue e não preza o encadeamento linear das palavras. A topografia caótica do ciberespaço, a fragmentação de arquivos lincados à mercê do sujeito-navegador, a tagarelice de vozes emergentes não se sabe de onde nem de quem, a permanente remissão a elas para instalar o dito, o efeito de liberdade (e desorientação) da página eletrônica e a possibilidade de escrita e leitura em vários lugares em curto intervalo de tempo dão conta de novas condições de produção que exigem nova formulação teórica e, por conseguinte, um novo conceito de autoria. 
A título de ensaio, talvez se possa pensar a autoria instalada em cada mensagem, em cada frase, em cada inscrição de linguagem, tangenciando da preocupação de ler o todo, a seqüência, o encadeamento e os mecanismos de reatroação do sujeito. Em cada link, a tentativa de materializar um fragmento de dizer e de autor; em cada nó da rede, um movimento isolado de escrever-se como posição que não contém a deriva, mas sobrevive a ela. Construindo uma analogia com o início desse artigo: em cada tela, um único traço significa um quadro inteiro sem a preocupação de formular um diálogo entre as partes.

\section{A título de conclusão:}

As implicações da autoria na rede não se esgotam na constatação de que a leitura do arquivo e a rede da memória são fundamentais para a inscrição de sujeitos e sentidos na teia digital, até porque isso já foi concluído em trabalhos anteriores (Pacífico 2002). Talvez "a novidade" seja afirmar que, na rede eletrônica, o sujeito-navegador manifesta-se a partir da voz e pela voz do(s) outro(s), reclamando a teia heterogênea de ditos alheios para fazer girar a sua condição de enunciador. Assim, a autoria é marcada por vozes que vão se apoiando em superfícies patinadas por outras vozes (sem as quais a navegação e a inscrição de sentidos ficam comprometidas), de modo a desenhar uma estranha cartografia de fragmentações de ditos, de retalhos de formulações e de retomadas de relatos, enrolados no pergaminho digital. Pergaminho este que se assemelha ao absurdo livro de areia de Borges (2000:79/80/81), em que o personagem se espanta ao reconhecer um livro sem início, sem meio e sem fim:

"A linha consta de um número infinito de pontos: o plano, de um número infinito de linhas; o volume, de um número infinito de planos; o hipervolume, de um número infinito de volumes... (...) Disse-me que seu livro se chamava Livro de Areia, porque nem o livro nem a areia têm princípio ou fim. (...) O número de páginas deste livro é exatamente infinito. Nenhuma é a primeira; nenhuma, a última. Não sei por que estão numeradas desse modo arbitrário. Talvez para dar a entender que os termos de uma série infinita admitem qualquer número (...) Se o espaço é infinito, estamos em qualquer ponto do espaço. Se o tempo é infinito, estamos em qualquer ponto do tempo".

Na rede, os links também são de areia e desenham um espaço fugidio e volátil, em que a autoria só pode ser pensada afetada pela heterogeneida- 
de do espaço com infinitas vozes, do tempo com infinitos ecos, da rede com infinitos pontos e do hipertexto com infinitos textos. O livro de silício desconstrói a direção das letras, das páginas e dos discursos, neblinando sentidos e sujeitos e promovendo a inscrição de novos gestos de autoria.

Recebido em junho de 2005

Aprovado em maio de 2006 E-mail: luciliamsr@ffclrp.usp.br

\section{REFERÊNCIAS BibLIOGRÁFICAS}

Araújo, Artur Vasconcellos. A noticia que é notícia: o blog jornalístico. Site www. pucsp.br/pos/cós/cps/arquivo (acessado em 10 de fevereiro de 2005).

Authier-Revuz, Jaqueline. 1990. Heterogeneidade(s) enunciativa(s). Cadernos de Estudos Lingüísticos 19, Unicamp.

Borges, Jorge Luis. 2000. Obras completas III. São Paulo: Editora Globo.

Komesu, Fabiana Cristina. 2004. Blogs e as práticas de escrita sobre si na Internet. In Marcuschi, Luis Antônio \& Antonio Carlos XaVIER (org). Hipertexto e gêneros textuais. Rio de Janeiro: Editora Lucerna.

Maldidier, Denise. 2003. A inquietação do discurso (re)ler Michel Pêcheux boje. Trad. Eni Orlandi. Campinas: Pontes.

Marcuschi, Luiz Antônio. 1999. Linearização, cognição e referência: o desafio do hipertexto. In: Linguas e Instrumentos Lingü̈́sticos. 3. Campinas: Editora Pontes: 21-46.

Melo, Cristina Teixeira Vieira de. 2004. A análise do discurso em contraponto à noção de acessibilidade ilimitada da Internet. In Marcuschi, Luis Antônio \& Antonio Carlos Xavier (org) Hipertexto e gêneros textuais. Rio de Janeiro: Editora Lucerna.

Oliveira, Maria Regina Momesso de. 2004. Weblogs: a exposição da subjetividade adolescente. In: Sargentini, Vanice \& Pedro NavarroBarbosa (org) Michel Foucault e os domínios da linguagem - discurso, poder, subjetividade. São Carlos: Claraluz Editora.

Orlandi, Eni P. 1996. A linguagem e seu funcionamento - as formas do discurso. Campinas: Pontes.

. 2003. Análise de Discurso princípios e procedimentos. $5^{\text {a }}$ ed. Campinas, SP: Pontes Editora. 
Pacífico, Soraya Maria Romano. 2002. Argumentação e autoria: o silenciamento do dizer. Tese de doutorado, Faculdade de Filosofia, Ciências e Letras de Ribeirão Preto da Universidade de São Paulo.

PAx, Salam. 2003. O blog de Bagdá - o diário de um jovem numa cidade bombardeada. São Paulo: Companhia das Letras.

PÊCheux, Michel. 1982. Ler o arquivo hoje. In: Orlandi, Eni. Gestos de leitura. (org) Campinas: Editora da Unicamp.

. 1993. Por uma análise automática do discurso: uma introdução à obra de Michel Pêcheux. In: GADET, F E Hak, T. (org.) Campinas: Editora da UNICAMP.

1999. Papel da memória. In: PÊCHeux, M. et alli. Papel da memória. Trad. José Horta Nunes. Campinas: Pontes.

Romão, Lucília Maria Sousa. 2002. O litígio discursivo materializado no MST: a ferida aberta na nação. Tese de doutorado, Faculdade de Filosofia, Ciências e Letras de Ribeirão Preto da Universidade de São Paulo, São Paulo. . 2004. Nós, desconhecidos, na grande rede. Revista Linguagem em (Dis) curso 5, n.1, jul./dez. Editora Unisul.

Saramago, José. 1998. Cadernos de Lanzarote. São Paulo: Companhia das Letras.

SCHittine, Denise. 2004. Blog: comunicação e escrita intima na internet. Rio de Janeiro: Civilização Brasileira.

Tfouni, Leda Verdiani. 2001. A dispersão e a deriva na constituição da autoria e suas implicações para uma teoria do letramento. In: SigNORINI, Inês (org) Investigando a relação orallescrito. Campinas, SP: Mercado de Letras. 